\title{
Thyroid function and thyroid autoantibodies in patients with chronic spontaneous urticaria
}

\author{
Magdalena Czarnecka-Operacz ${ }^{1}$, Anna Sadowska-Przytocka ${ }^{1}$, Dorota Jenerowicz ${ }^{1}$, Anna Szeliga ${ }^{2}, Z^{2 y g m u n t}$ Adamski $^{1}$, \\ Katarzyna Łącka ${ }^{3}$
}

${ }^{1}$ Department of Dermatology, Poznan University of Medical Sciences, Poznan, Poland ${ }^{2}$ Student's Scientific Society, Poznan University of Medical Sciences, Poznan, Poland

${ }^{3}$ Department of Endocrinology, Metabolism and Internal Medicine, Poznan University of Medical Sciences, Poznan, Poland

Adv Dermatol Allergol 2017; XXXIV (6): 566-572

DOI: https://doi.org/10.5114/ada.2017.72464

\begin{abstract}
Introduction: Chronic urticaria (CU) is a skin disease caused by autoantibodies against high affinity immunoglobulin $\mathrm{E}$ (IgE) receptor and against IgE. It is characterized by hives, erythematous wheals and redness present minimum twice a week for at least 6 weeks. It is observed that there is a strong association between CU and autoimmune diseases, such as autoimmune thyroiditis (AT).

Aim: To verify the frequency of AT in patients suffering from chronic spontaneous urticaria (CSU) and to confirm the coexistence of $\mathrm{CU}$ and AT in the Polish population.

Material and methods: One hundred and forty-eight patients with CSU were included to the study. The presence of anti-thyroperoxydase antibodies (anti-TPO) and anti-thyroglobulin antibodies (anti-Tg) was checked and thyrotropin (TSH), free thyroxine (fT4) and free triiodothyronine (fT3) concentration was measured. Results were compared with outcomes in a group of 35 patients with no history of skin disease.

Results: Thirty-three patients were diagnosed with AT. Frequency of elevated anti-TPO $(p=0.0045)$ and anti-Tg $(p=$ 0.013) levels was much higher in patients with CU. A comparison of the current study and previous ones was conducted. In a group with CU, there was a higher risk of elevated anti-TPO $(\mathrm{OR}=6.69)$ and anti-Tg $(\mathrm{OR}=6.01)$ levels. Conclusions: There is a statistically significant difference in the presence of AT between the patients with CU and the whole population. Doctors should consider examining patients with CU for AT. Adequate therapy and guidance for patients could be implemented at an early stage of thyroid disease and help induce remission of skin disorders.

Key words: chronic urticaria, autoimmune thyroiditis, thyroid, anti-thyroperoxydase antibodies, anti-thyroglobulin antibodies, autoimmunity.
\end{abstract}

\section{Introduction}

Chronic urticaria (CU) is a common skin disease, which affects about $0.1-1 \%$ of the population [1]. Urticaria affects $15-25 \%$ of people at least once in their lifetime [2]. It is diagnosed using criteria including hives, persistent or transitory widespread erythematous wheals with itching and redness present minimum twice a week for at least 6 weeks $[1,3]$. In about $60 \%$ of patients presenting characteristic lesions, the disorder is associated with serological factors. It is related to higher immunoglobulin E (IgE) production and T-cell induced cytokine production, secretion of vasoactive substances such as histamine, prostaglandins, kinins and other proinflammatory substances [1, 2, 4, 5]. In about 55\% of cases of CU (excluding CU with known pathogenesis), the spon- taneous type is confirmed, $45 \%$ of the patients present an autoimmune type, called chronic autoimmune urticaria. Now it is known that CU is caused by the autoimmune process with the presence in 10-40\% of cases of circulating IgG autoantibodies against the high affinity IgE receptor (FceR1) and less commonly (in 5-10\%) with IgG antibodies against IgE or IgG antibodies linking to $34 \mathrm{kD} \alpha$ subunit of the IgE receptor [6-8]. Those autoantibodies cause an activation of basophiles and mast cells, secretion of histamine and infiltration of cells connected with inflammation. Less patients have some factors that can cause a mastocyte degranulation, but they have not been found yet. Furthermore, in patients with chronic spontaneous urticaria (CSU), in about $25-30 \%$ of cases, the presence of anti-thyroid antibodies was revealed and

Address for correspondence: Dorota Jenerowicz MD, PhD, Department of Dermatology, Poznan University of Medical Sciences, 49 Przybyszewskiego St, 60-355 Poznan, Poland, phone: +48 608470 536, e-mail: djenerowicz@yahoo.com Received: 12.04 .2016 , accepted: 17.10.2016. 
Hashimoto disease was diagnosed [9]. This group has a higher frequency of DR alleles, which are connected with autoimmunity, and is more exposed to severity of CU [8]. Patients with CU and thyroid autoimmunity (TA) have a higher risk of angioedema and because of that they require specific treatment [10].

Autoimmune thyroiditis (AT) is the most common inflammatory disease of the thyroid gland. It is proven that Hashimoto disease is a polygenic disorder, in which genetic, environmental and infectious factors play a role in its pathogenesis [11].

\section{Aim}

The aim of a study was to explore the link between the thyroid function in patients with CSU and AT by checking the thyroid function and autoimmune processes of thyroid in patients suffering from CSU and to compare it with the thyroid function in healthy subjects.

\section{Material and methods}

One hundred and forty five women and three men at the age of 16 to 80 (mean: 42 years, median: 41 years, range: 23-67) were included to the study. Chronic urticaria was diagnosed using the clinical criteria (symptoms occurring every day or almost every day for 6 weeks). Eighty of them suffered from angioedema on admission. Patients were treated for urticaria with rupatadine, bilastine, fexofenadine, hydroxyzine and montelukast.

The control group was composed of sex- and agematched healthy volunteers with no history of CU or any thyroid disease. There were 22 women and 13 men (63\%/37\%) at the age of 23 to 67 (mean: 38, median: 33, range: $16-80$ ). Patients with autoimmune diseases and neoplastic diseases were excluded from the study.

The concentration of thyrotropin (TSH) (normal: 0.27-4.20 $\mu \mathrm{lUm} / \mathrm{l}$ ), free thyroxine (fT4) (normal: 11.5-21.0 $\mathrm{pmol} / \mathrm{l}$ ), free triiodothyronine (fT3) (normal: 3.90-6.70 pmol/l), anti-thyroperoxydase antibodies (anti-TPO) and anti-thyroglobulin antibodies (anti-Tg) was measured. The presence of anti-TPO in concentration greater than $34 \mathrm{lU} / \mathrm{ml}$ and anti-Tg levels in titers greater than $115 \mathrm{IU} /$ $\mathrm{ml}$ were considered elevated. The concentration of antiTg was measured by conducting radioimmunological tests from BRAHMS Diagnostic GMBH. Levels of antiTPO immunoglobulins was measured by RIA tests from BRAHMS Diagnostic GMBH. Electro-chemiluminescence immunoassay was used to check the concentration of TSH using a set from Roche Diagnostics Switzerland. The same assay was used to measure levels of free T3 and T4 in serum with sets from Roche Diagnostics Switzerland.

The study was approved by a local ethical committee (ethical approval number KB: 644/09) and patients signed informed written consent.

\section{Statistical analysis}

Quantitative characteristics were described by mean, minimum, maximum and median. Because groups of patients were inconsistent with normal distribution, nonparametric statistics were used for statistical analyses. For comparison of features in the studied and control group, Mann-Whitney or Fischer test was used. The results with $p<0.05$ were considered as statistically sig-
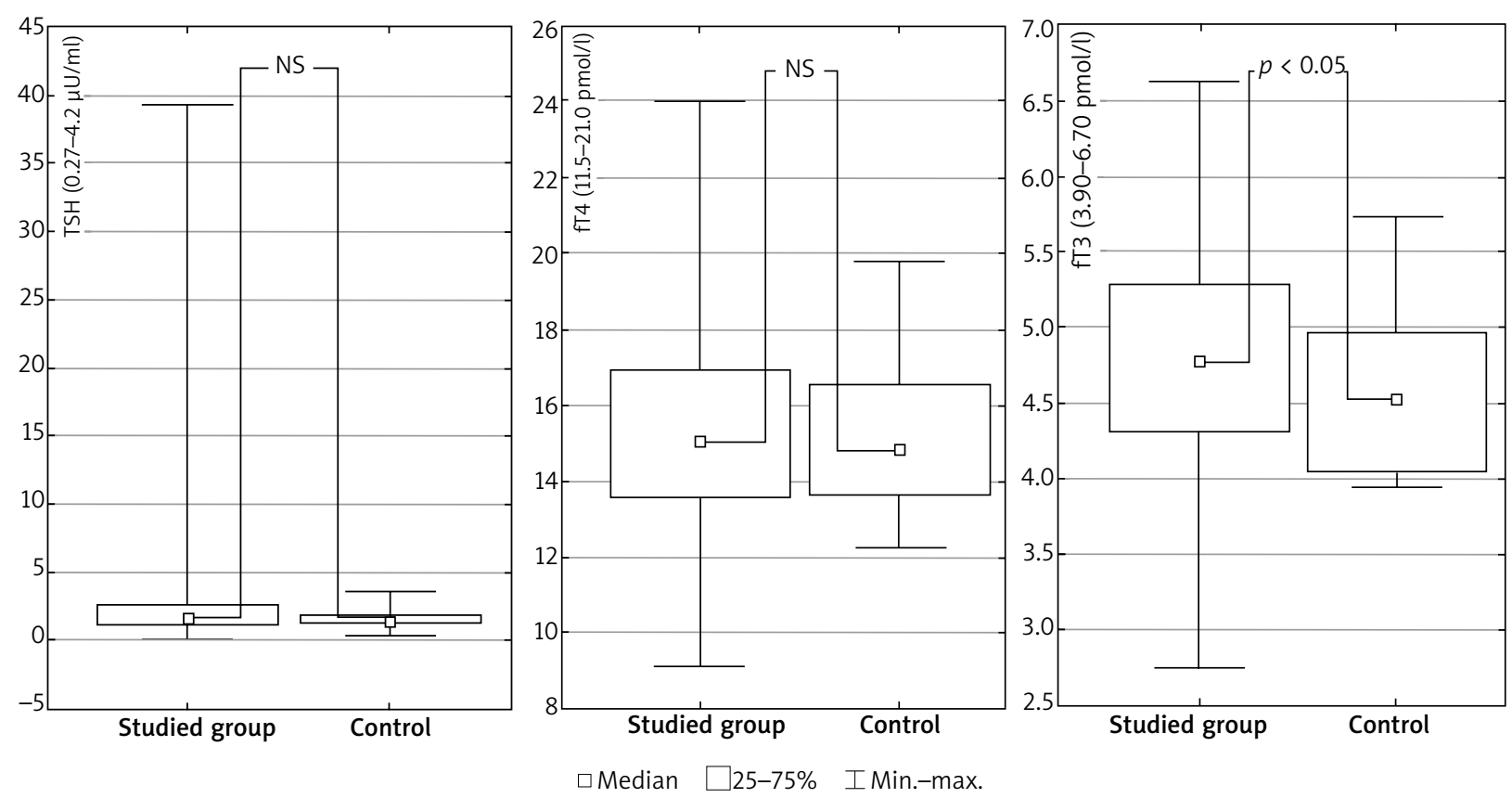

Figure 1. Serum TSH, fT4 and fT3 concentration in the studied group compared to the controls 

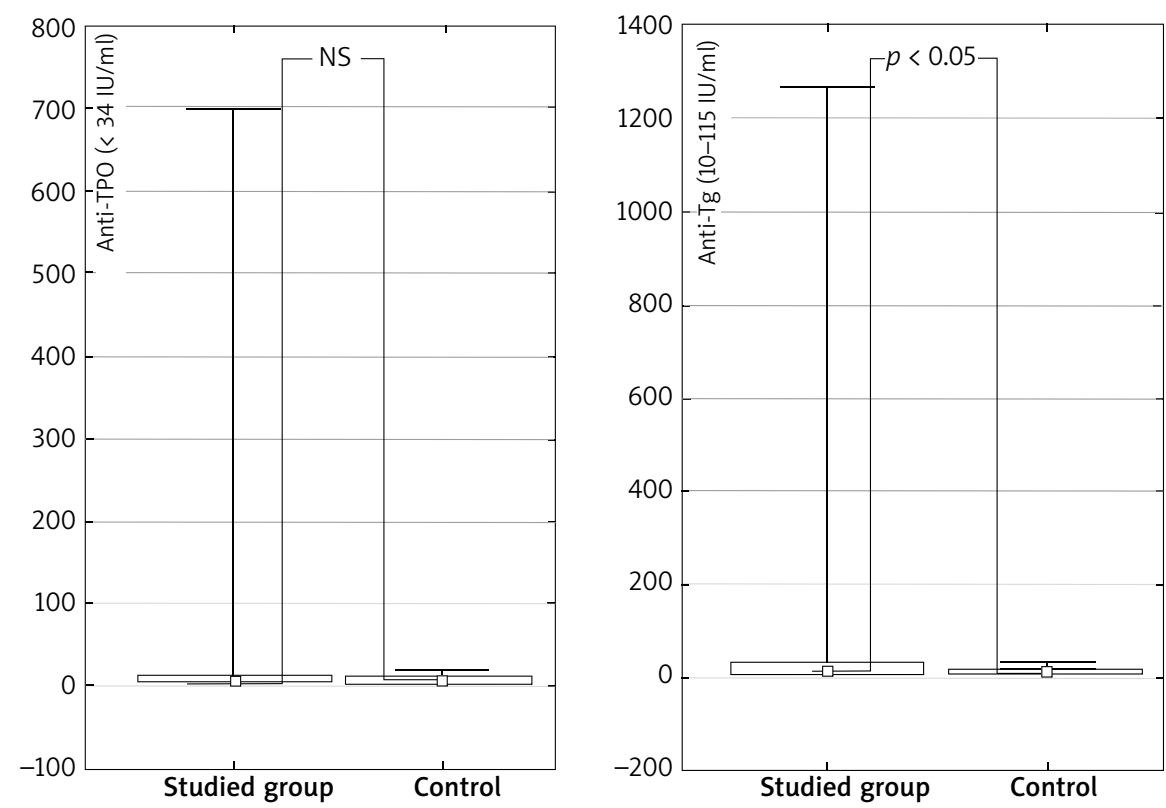

$\square$ Median $\square 25-75 \% \quad$ IMin.-max.

Figure 2. Serum anti-TPO and anti-Tg levels in the studied group compared to the controls

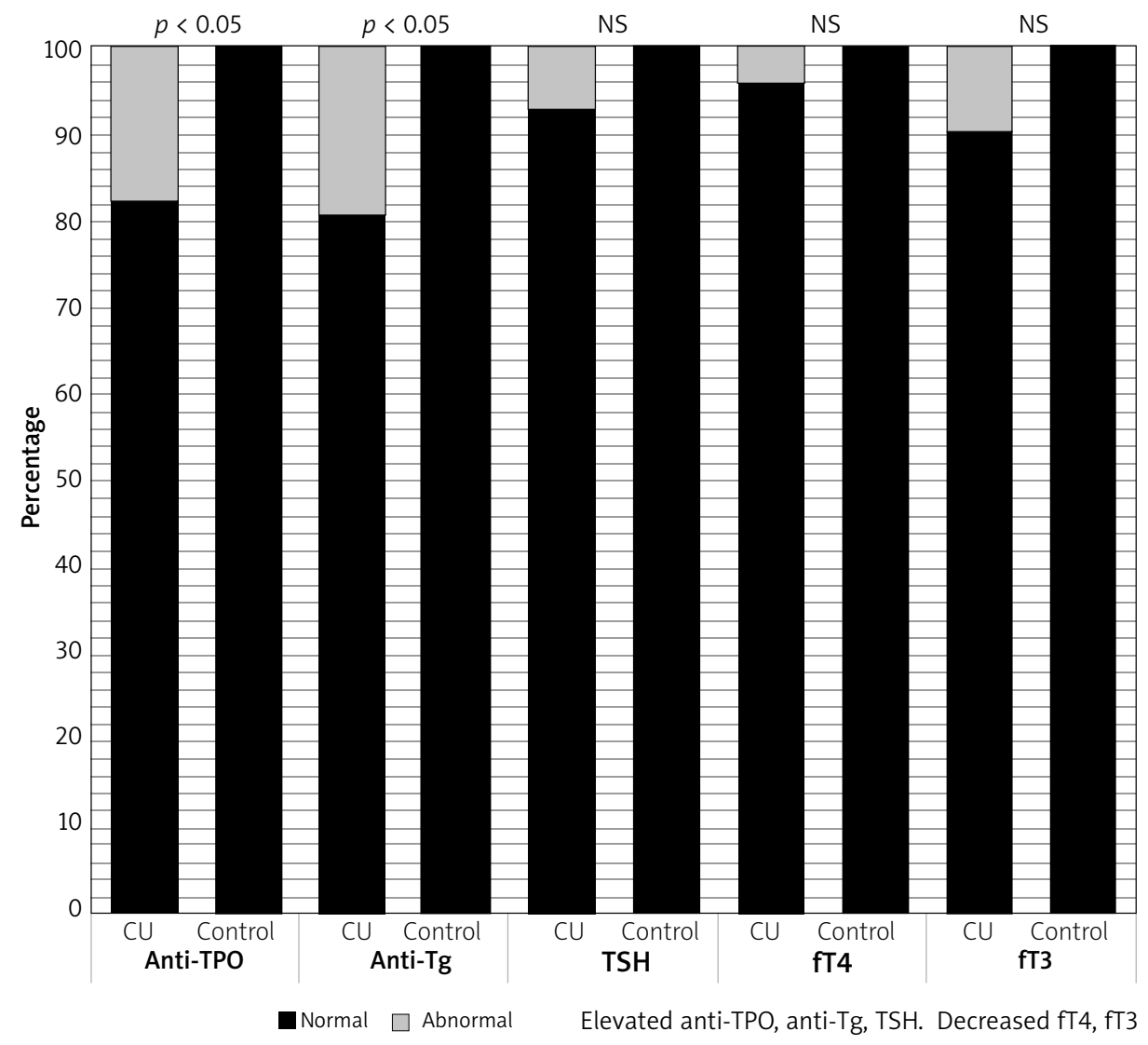

Figure 3. Frequency of the elevated concentration of anti-thyroid antibodies and thyroid hormones 
nificant. The statistical tests were carried out with the software Statistica 12 from StatSoft.

\section{Results}

Anti-TPO, anti-Tg, fT4, fT3 and TSH concentration was measured. Median values were $9.0 \mathrm{IU} / \mathrm{ml}, 16.0 \mathrm{lU} / \mathrm{ml}$, $15.1 \mathrm{pmol} / \mathrm{l}, 4.8 \mathrm{pmol} / \mathrm{l}$ and $1.7 \mathrm{\mu U} / \mathrm{ml}$, respectively, in patients with $\mathrm{CU}$ and $8.0 \mathrm{IU} / \mathrm{ml}, 12.0 \mathrm{IU} / \mathrm{ml}, 14.9 \mathrm{pmol} / \mathrm{l}$, $4.5 \mathrm{pmol} / \mathrm{l}$ and $1.4 \mathrm{\mu U} / \mathrm{ml}$, respectively, in the control group. There is a statistically significant difference between groups as to the concentration of fT3 ( $p=0.03)$ (Figure 1) and anti-Tg ( $p=0.003$ ) (Figure 2). There was no statistical difference between the concentration of antiTPO, TSH and fT4.

In the group of patients with CU, 23 of them had elevated anti-TPO, 19 - anti-Tg, 9 had elevated both anti-TPO and anti-Tg, 9 had an elevated concentration of TSH, 5 had a decreased concentration of fT4 and 12 - decreased fT3. Thirty-three patients were diagnosed with AT, 24 of them were euthyroid, 5 were subclinical hypothyroid and 4 had hypothyroidism.

There was a statistically significant difference between groups as to the number of patients with elevated anti-TPO $(p=0.004)$ and anti-Tg $(p=0.02)$, but there was no statistically significant difference as to the number of patients with an elevated concentration $\mathrm{fT} 4$, $\mathrm{fT} 3$ and TSH (Figure 3).

The study showed that in a group of patients with anti-TPO >100, there was a significantly higher percentage of patients with anti-Tg $>100$. Moreover, there was a statistically significant difference in frequency of anti$\mathrm{Tg}>100 \mathrm{IU} / \mathrm{ml}$ in the group of patients with and without angioedema on admission (Figure 4).

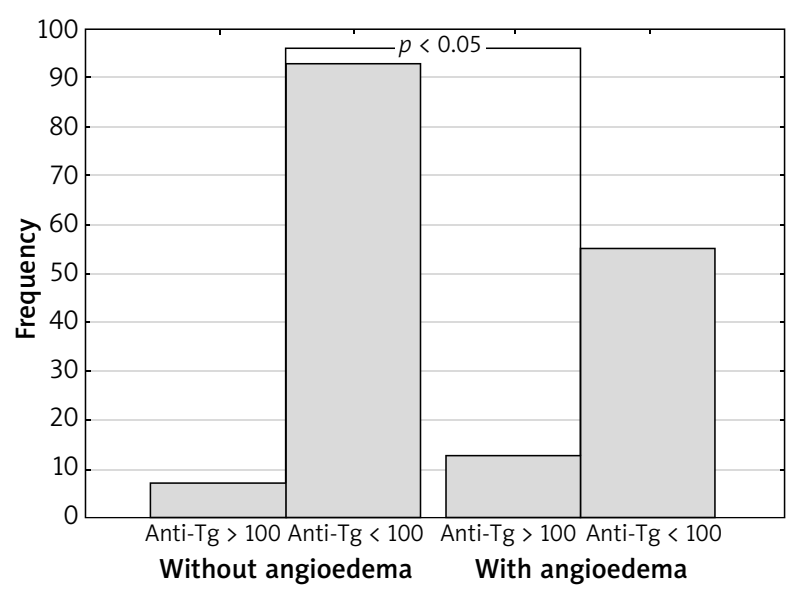

Figure 4. Frequency of anti-Tg $>100$ in patients with and without angioedema on admission

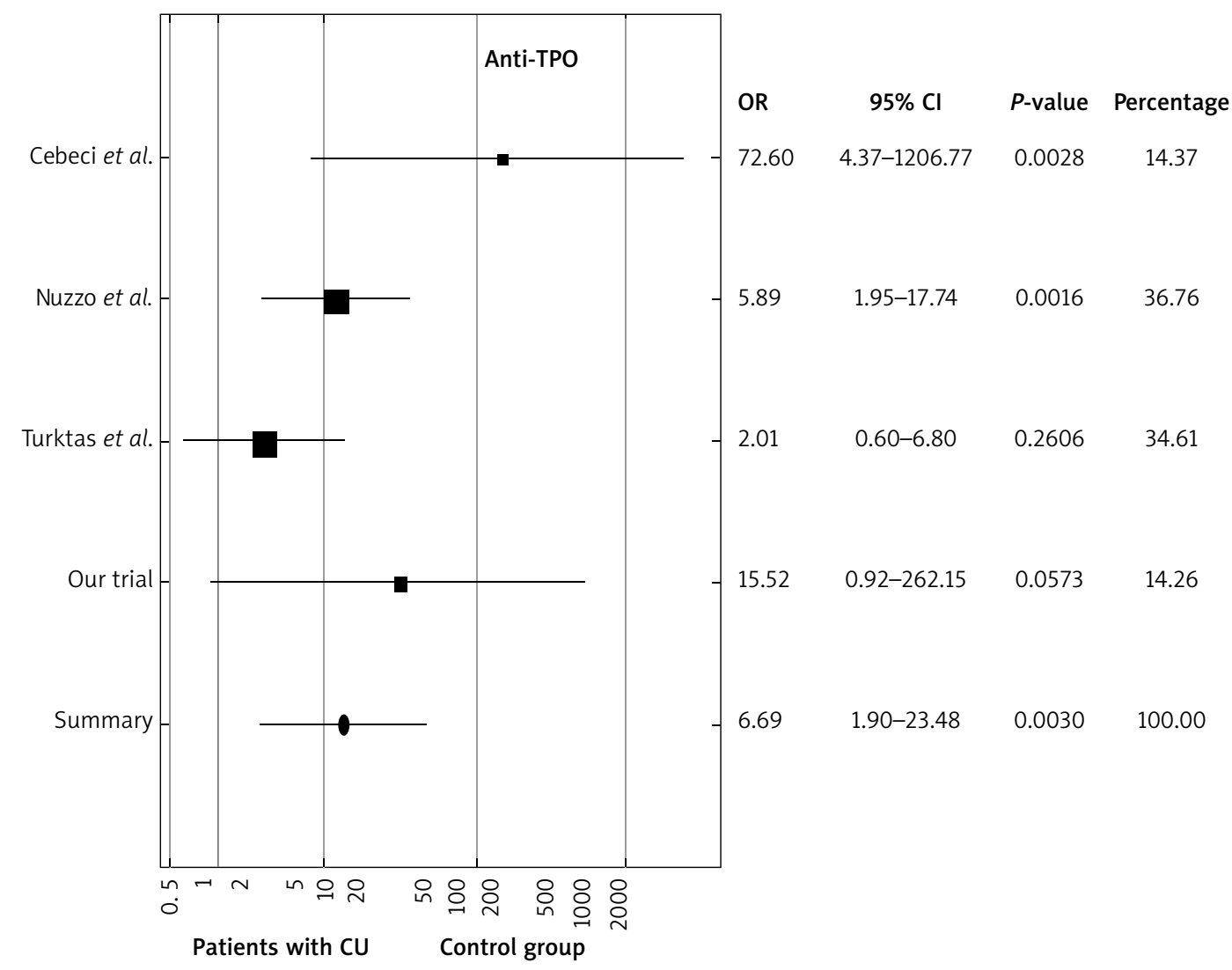

Figure 5. Comparison of frequency of elevated anti-TPO in 4 studies [11-13] 


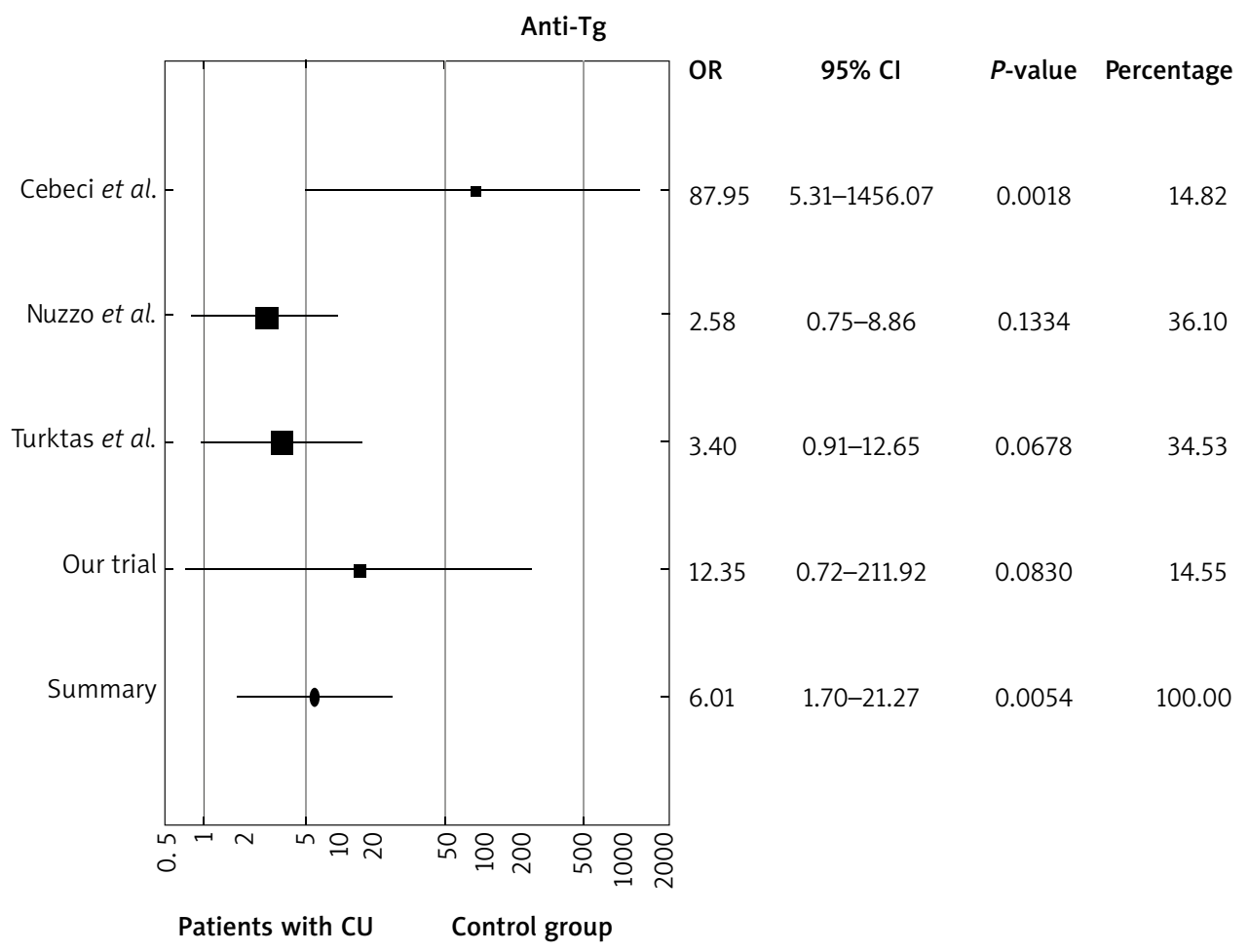

Figure 6. Comparison of frequency of elevated anti-Tg in 4 studies [11-13]

Comparing 4 investigations, it was observed that $\mathrm{CU}$ is connected with an increased concentration of anti-TPO and anti-Tg (which are markers of TA). It was noticed that there is a difference between groups as to concentration of thyroid hormones [12-14].

A comparison of the described examination with 3 other studies, which investigated coexistence of CU and AT, was made. There was a significantly higher likelihood of elevated levels of anti-TPO $(\mathrm{OR}=6.65)$ (Figure 5) and anti-Tg $(O R=4.89)$ in patients with $C U$ than in the control group (Figure 6). Nevertheless, there was no comparison of anti-TPO and anti-Tg levels, only a comparison of the number of patients with abnormal anti-TPO or anti-Tg levels relative to a normal anti-TPO or anti-Tg concentration, specific for each test and laboratory was conducted.

\section{Discussion}

An association between CSU and AT has been observed since 1983, when the patient with urticaria and thyroiditis was described by Midelfart et al. [15]. At the same time, Leznoff et al. [16] detected elevated thyroid microsomal antibodies (TMA) in $12.1 \%$ of CU patients and in only $5.6 \%$ of individuals from the control group, suspecting that CU may have an autoimmune basis [16]. After that survey, a study of 90 patients with CU, angioedema and TA was performed. The association between
CU and TA was significant, but treatment with levothyroxine did not have an influence on skin diseases [17].

In our study, we confirmed a significant difference between CU patients and healthy subjects as to the fT3 and anti-TG concentration. Moreover, we observed that patients with CU more frequently had an elevated concentration of anti-thyroid antibodies than individuals from the control group. Our observations remain in compliance with other authors' results. In a study performed by Turktas et al. [14], the concentration of TMA and anti-Tg in patients with CU and angioedema was measured. A statistically significant difference between the concentration of TMA and anti-Tg in both groups of patients was found [14]. Ryhal et al. [18] noticed that the concentration of anti-TPO was significantly higher in patients with CU than in the control group [18]. Also other numerous prospective case-control studies revealed a significantly higher concentration of anti-thyroid antibodies in the group of patients with CU than in the control group [19-21].

On the other hand, a concentration of anti-TPO, anti$\mathrm{Tg}$ and anti-TSH-receptor antibodies was assayed by Zauli et al. [22] in patients suffering from CU with a known cause and in CSU - the difference was not statistically significant. In the study it was shown that TA is connected with urticaria regardless of pathogenesis.

Recent literature data suggest that CU may be associated with other thyroid gland pathologies. Four cases of urticaria in thyroid carcinoma have been described. 
Moreover, urticaria resolved after removal of tumors [23]. There were also two cases of Graves' disease and CU. Those patients did not respond to antihistamine drugs, but symptoms of urticaria disappeared after corresponding treatment with anti-thyroid drugs [24].

Although the connection between CU and AT is unclear, it is known that linking of thyroid autoantibodies to receptors of IgE on mastocytes may cause a histamine secretion [25]. In a study conducted in 2001 by Kandeel et al. [26], it was revealed that only patients with CSU and AT had perivascular fibrin deposits in skin biopsies and anti-FceRl antibodies in serum, which can lead to secretion of histamine from mastocytes. There were no differences in expression of selected CD and in oligoclonal T-lymphocyte subpopulation [26]. It is not proven that anti-thyroid antibodies are the cause of $\mathrm{CU}$, these are rather co-morbid phenomena [7]. In another study it was shown that only $10 \%$ of patients with CU and IgG antithyroid antibodies have IgE anti-thyroid antibodies, what proves that those autoantibodies cannot be a cause of $\mathrm{CU}[27]$.

Another interesting issue is the possibility to induce remission of $\mathrm{CU}$ as a consequence of thyroid gland pathology treatment. Gaig et al. [28] suggest that treating autoimmune thyroid diseases with levothyroxine or methimazole can improve the results of autologous serum skin tests (ASST) and overall condition of the patient. However, other authors suggest that results of ASST may not stay in compliance with TA [29], and there is no statistically significant difference in frequency of AT in patients with positive and negative ASST [30]. If it comes to clinical implications, Rumbyrt et al. [31] found that treatment using levothyroxine of euthyroid patients with anti-thyroid antibodies and CU leads to resolution of skin lesions. Moreover, after the treatment was stopped, urticaria returned and after introducing the treatment once again the symptoms resolved [31]. In another study it was revealed that most patients suffering from CU and TA are euthyroid and achieved the best remissions during levothyroxine supplementation, however patients with clinical or subclinical thyroid disorders have to take treatment corresponding to their disease [32]. In another study it was suggested that levothyroxine can be an important part of treatment for patients with $\mathrm{CU}$ and TA. The results of the treatment with ketotifen and levothyroxine were compared. Ketotifen treatment provided significant relief of symptoms, but these beneficial effects were observed only during ongoing treatment and urticaria reappeared in all patients during the drug-free follow-up period. On the other hand, 18 of 30 patients completely improved and 3 patients partially improved with levothyroxine treatment [33]. Although the above-described issue was not the aim of our paper, it would be interesting to conduct an observation on the influence of levothyroxine on the activity of urticaria in patients presenting TA.

The connection between CU and TA is unquestioned and there are many implications in treatment of those diseases. Nevertheless, the pathogenesis and molecular basis of connection is still unknown. It is very important to find an explanation of those processes because they may have an influence on therapy of patients with $\mathrm{CU}$ and AT.

\section{Conflict of interest}

The authors declare no conflict of interest.

\section{References}

1. Abd El-Azim M, Abd El-Azim S. Chronic autoimmune urticaria: frequency and association with immunological markers. $J$ Investig Allergol Clin Immunol 2011; 21: 546-50.

2. Krupa Shankar DS, Ramnane M, Rajouria A. Etiological approach to chronic urticaria. Indian J Dermatol 2010; 55: 33-8.

3. Viswanathan RK, Biagtan MJ, Mathur SK. The role of autoimmune testing in chronic idiopathic urticaria. Ann Allergy Asthma Immunol 2012; 108: 337-41.

4. O'Donnell BF, Francis DM, Swana GT, et al. Thyroid autoimmunity in chronic urticaria. Br J Dermatol 2005; 153: 331-5.

5. Aktar S, Akdeniz N, Ozkol HU, et al. The relation of autologous serum and plasma skin test results with urticarial activity score, sex and age in patients with chronic urticaria. Postep Derm Alergol 2015; 32: 173-8.

6. Greaves MW, Tan KT. Chronic urticaria: recent advances. Clin Rev Allergy Immunol 2007; 33: 134-43.

7. Rottem M. Chronic urticaria and autoimmune thyroid disease: is there a link? Autoimmun Rev 2003; 2: 69-72.

8. Kaplan AP, Greaves M. Pathogenesis of chronic urticaria. Clin Exp Allergy 2009; 39: 777-87.

9. Mozena JD, Tińana A, Negri J, et al. Lack of a role for crossreacting anti-thyroid antibodies in chronic idiopathic urticaria. J Invest Dermatol 2010; 130: 1860-5.

10. Missaka RF, Penatti HC, Silvares MR, et al. Autoimmune thyroid disease as a risk factor for angioedema in patients with chronic idiopathic urticaria: a case-control study. Sao Paulo Med J 2012; 130: 294-8.

11. Lacka K, Maciejewski A. Current views on the etiopathogenesis of autoimmune thyroiditis (Hashimoto's disease). Pol Merkur Lekarski 2011; 30: 132-8.

12. Nuzzo V, Tauchmanova L, Colasanti P, et al. Idiopathic chronic urticaria and thyroid autoimmunity: experience of a single center. Dermatoendocrinology 2011; 3: 255-8.

13. Cebeci F, Tanrikut A, Topcu E, et al. Association between chronic urticaria and thyroid autoimmunity. Eur J Dermatol 2006; 16: 402-5.

14. Turktas I, Gokcora N, Demirsoy S, et al. The association of chronic urticaria and angioedema with autoimmune thyroiditis. Int J Dermatol 1997; 36: 187-90.

15. Midelfart K, Moseng D, Kavli G, et al. A case of chronic urticaria and vitiligo, associated with thyroiditis, treated with PUVA. Dermatologica 1983; 167: 39-41.

16. Leznoff A, Josse RG, Denburg J, et al. Association of chronic urticaria and angioedema with thyroid autoimmunity. Arch Dermatol 1983; 119: 636-40.

17. Leznoff A, Sussman GL. Syndrome of idiopathic chronic urticaria and angioedema with thyroid autoimmunity: a study of 90 patients. J Allergy Clin Immunol 1989; 84: 66-71.

18. Ryhal B, DeMera RS, Shoenfeld Y, et al. Are autoantibodies present in patients with subacute and chronic urticaria? J Investig Allergol Clin Immunol 2001; 11: 16-20. 
19. Verneuil L, Leconte C, Ballet JJ, et al. Association between chronic urticaria and thyroid autoimmunity: a prospective study involving 99 patients. Dermatology 2004; 208: 98-103.

20. Palma-Carlos AG, Palma-Carlos ML. Chronic urticaria and thyroid auto-immunity. Eur Ann Allergy Clin Immunol 2005; 37: 143-6.

21. Aamir IS, Tauheed S, Majeed F, et al. Serum antithyroid antibodies in female patients with chronic urticaria. J Coll Physicians Surg Pak 2008; 18: 498-501.

22. Zauli D, Deleonardi G, Foderaro S, et al. Thyroid autoimmunity in chronic urticaria. Allergy Asthma Proc 2001; 22: 93-5.

23. Manganoni AM, Tucci G, Venturini M, et al. Chronic urticaria associated with thyroid carcinoma: report of 4 cases. I Investig Allergol Clin Immunol 2007; 17: 192-5.

24. Bansal AS, Hayman GR. Graves' disease associated with chronic idiopathic urticaria: 2 case reports. J Investig Allergol Clin Immunol 2009; 19: 54-6.

25. Delèvaux I, André M, Tridon A, et al. Chronic urticaria and Hashimoto-Hashimoto's thyroiditis: report of 6 cases. Rev Med Intern 2001; 22: 232-7.

26. Kandeel AA, Zeid M, Helm T, et al. Evaluation of chronic urticaria in patients with Hashimoto thyroiditis. J Clin Immunol 2001; 21: 335-47.

27. Concha LB, Chang CC, Szema AM, et al. IgE antithyroid antibodies in patients with Hashimoto's disease and chronic urticaria. Allergy Asthma Proc 2004; 25: 293-6.

28. Gaig P, García-Ortega P, Enrique E, et al. Successful treatment of chronic idiopathic urticaria associated with thyroid autoimmunity. I Investig Allergol Clin Immunol 2000; 10 : 342-5.

29. Vermeulen C, Mathelier-Fusade P, Rouquette AM, et al. Chronic urticaria, thyroiditis and autologous serum test. Ann Dermatol Venereol 2003; 130: 1115-8

30. Yadav S, Kanwar A, Parsad D, et al. Chronic idiopathic urticaria and thyroid autoimmunity: perplexing association. Indian J Dermatol 2013; 58: 325.

31. Rumbyrt JS, Katz JL, Schocket AL. Resolution of chronic urticaria in patients with thyroid autoimmunity. J Allergy Clin Immunol 1995; 96: 901-5.

32. Zauli D, Grassi A, Ballardini G, et al. Thyroid autoimmunity in chronic idiopathic urticaria: implications for therapy. Am J Clin Dermatol 2002; 3: 525-8.

33. Karaayvaz M, Calişkaner Z, Turan M, et al. Levothyroxine versus ketotifen in the treatment of patients with chronic urticaria and thyroid autoimmunity. J Dermatolog Treat 2002; 13: $165-72$ 